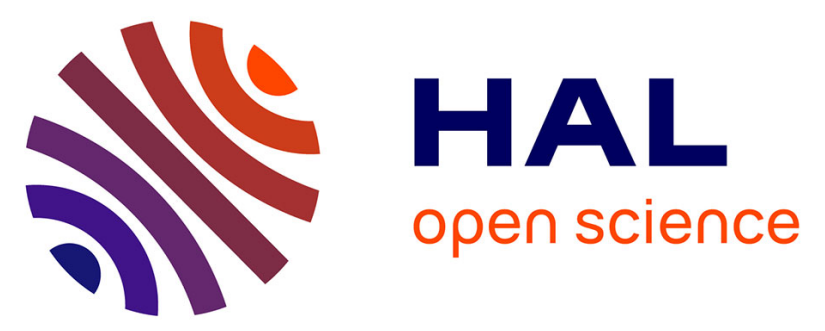

\title{
Spatiotemporal distribution of the seismicity along the Mid-Atlantic Ridge north of the Azores from hydroacoustic data: Insights into seismogenic processes in a ridge-hot spot context
}

Jean Goslin, Julie Perrot, Jean-Yves Royer, Christophe Martin, Nuno Lourenço, J. Luis, R. P. Dziak, H. Matsumoto, M.J. Fowler, C.G. Fox, et al.

\section{To cite this version:}

Jean Goslin, Julie Perrot, Jean-Yves Royer, Christophe Martin, Nuno Lourenço, et al.. Spatiotemporal distribution of the seismicity along the Mid-Atlantic Ridge north of the Azores from hydroacoustic data: Insights into seismogenic processes in a ridge-hot spot context. Geochemistry, Geophysics, Geosystems, 2012, 13 (2), pp.Q02010. 10.1029/2011GC003828 . insu-00681683

\section{HAL Id: insu-00681683 \\ https://hal-insu.archives-ouvertes.fr/insu-00681683}

Submitted on 22 Sep 2012

HAL is a multi-disciplinary open access archive for the deposit and dissemination of scientific research documents, whether they are published or not. The documents may come from teaching and research institutions in France or abroad, or from public or private research centers.
L'archive ouverte pluridisciplinaire HAL, est destinée au dépôt et à la diffusion de documents scientifiques de niveau recherche, publiés ou non, émanant des établissements d'enseignement et de recherche français ou étrangers, des laboratoires publics ou privés. 


\title{
Spatiotemporal distribution of the seismicity along the Mid-Atlantic Ridge north of the Azores from hydroacoustic data: Insights into seismogenic processes in a ridge-hot spot context
}

\author{
J. Goslin, J. Perrot, J.-Y. Royer, and C. Martin \\ Domaines Océaniques, UMR 6538, Université Européenne de Bretagne, Université de Brest, CNRS, \\ IUEM, Place N. Copernic, F-29280 Plouzané, France \\ N. Lourenço \\ Estrutura de Missão para a Extensão da Plataforma Continental, 2770-057 Paço de Arcos, Portugal
}

\section{J. Luis}

Centro de Investigação Marinha e Ambiental, Universidade do Algarve, Campus de Gambelas, 8005-139 Faro, Portugal

\author{
R. P. Dziak, H. Matsumoto, J. Haxel, and M. J. Fowler \\ Pacific Marine Environmental Laboratory, Hatfield Marine Science Center, Oregon State University, \\ NOAA, Newport, Oregon 97365, USA
}

C. G. Fox

NGDC, NESDIS, NOAA, Boulder, Colorado 80303, USA

\section{A. T.-K. Lau \\ Pacific Marine Environmental Laboratory, Hatfield Marine Science Center, Oregon State University, NOAA, Newport, Oregon 97365, USA}

\section{S. Bazin \\ Institut de Physique du Globe de Paris, Paris, France \\ Now at Norwegian Geotechnical Institute, Sognsveien 72, N-0855 Oslo, Norway}

[1] The seismicity of the North Atlantic was monitored from May 2002 to September 2003 by the 'SIRENA array' of autonomous hydrophones. The hydroacoustic signals provide a unique data set documenting numerous low-magnitude earthquakes along the section of the Mid-Atlantic Ridge (MAR) located in a ridge-hot spot interaction context. During the experiment, 1696 events were detected along the MAR axis between $40^{\circ} \mathrm{N}$ and $51^{\circ} \mathrm{N}$, with a magnitude of completeness level of $m_{b} \approx 2.4$. Inside the array, location errors are in the order of $2 \mathrm{~km}$, and errors in the origin time are less than $1 \mathrm{~s}$. From this catalog, 15 clusters were detected. The distribution of source level (SL) versus time within each cluster is used to discriminate clusters occurring in a tectonic context from those attributed to non-tectonic (i.e. volcanic or hydrothermal) processes. The location of tectonic and non-tectonic sequences correlates well with regions with positive and negative Mantle Bouguer Anomalies (MBAs), indicating the presence of thinner/colder and thicker/ warmer crust respectively. At the scale of the entire array, both the complete and declustered catalogs derived from the hydroacoustic signals show an increase of the seismicity rate from the Azores up to 
$43^{\circ} 30^{\prime} \mathrm{N}$ suggesting a diminishing influence of the Azores hot spot on the ridge-axis temperature, and well correlated with a similar increase in the along-axis MBAs. The comparison of the MAR seismicity with the Residual MBA (RMBA) at different scales leads us to think that the low-magnitude seismicity rates are directly related to along-axis variations in lithosphere rheology and temperatures.

Components: 9300 words, 10 figures, 2 tables.

Keywords: Azores hot spot-ridge interaction; autonomous hydrophone; seismicity; spreading center.

Index Terms: 7230 Seismology: Seismicity and tectonics (1207, 1217, 1240, 1242); 8416 Volcanology: Mid-oceanic ridge processes (1032, 3614); 9325 Geographic Location: Atlantic Ocean.

Received 4 August 2011; Revised 20 January 2012; Accepted 20 January 2012; Published 24 February 2012.

Goslin, J., et al. (2012), Spatiotemporal distribution of the seismicity along the Mid-Atlantic Ridge north of the Azores from hydroacoustic data: Insights into seismogenic processes in a ridge-hot spot context, Geochem. Geophys. Geosyst., 13, Q02010, doi:10.1029/2011GC003828.

\section{Introduction}

[2] Studies of active accretion processes at the axes of slow spreading mid-ocean ridges, either based on field studies [Lin et al., 1990; Gente et al., 1995; Thibaud et al., 1998] or on analog or numerical modeling [Gac et al., 2003, 2006] have promoted the now well-accepted image that seafloor spreading results from a succession, in space and time, of magmatic and tectonic episodes. In such models, most of the heat output focuses near the centers of ridge segments, resulting from the emplacement of greater amounts of new basaltic crust [Bell and Buck, 1992; Cannat, 1993; Gente et al., 1995; Magde et al., 1997]. In contrast, seafloor spreading at relatively colder segment-ends is mostly accounted for by tectonic processes, resulting in the emplacement of a thinner crust with a thicker brittle upper layer [Lin et al., 1990; Bell and Buck, 1992; Cannat, 1993; Gac et al., 2003, 2006]. Such variations in crustal and lithospheric thermal state at the segment scale directly influence the rheology of the crust and lithosphere. Moreover, these alongaxis variations in the rheology should be reflected by the along-axis spatiotemporal distributions of the seismicity; testing this intuitive idea requires access to low-level (background) seismicity recorded over large sections of mid-ocean ridges.

[3] Here we report the results of a hydroacoustic experiment carried out over a $>1000 \mathrm{~km}$-long section of the north Mid-Atlantic Ridge. There are several previous examples of experiments where arrays of autonomous underwater hydrophones (AUH) were deployed for a year on the flanks of mid-oceanic ridges were able to capture the lowlevel seismicity associated with seafloor spreading processes [e.g., Dziak et al., 1995; Fox et al., 2001; Dziak, 2001; Smith et al., 2002; Goslin et al., 2005]. Earthquakes occurring at mid-ocean ridge axes generate both seismic phases that will travel within the lithosphere and a hydroacoustic phase which will propagate in the water column and through the SOund Fixing And Ranging (SOFAR) channel, over long distances $(>1000 \mathrm{~km})$ with very little attenuation [Fox et al., 1994]. This waterborne phase results from the conversion of seismic to acoustic waves at the crust/water interface on the seafloor [Talandier and Okal, 1998; Okal, 2008; Balanche et al., 2009]. The SOFAR channel is a low-velocity layer in the water column, typically located at depths from 700 to $1000 \mathrm{~m}$ at midlatitudes in the North Atlantic Ocean, and thus acts as a waveguide trapping acoustic signals. The acoustic phase is referred to as the Tertiary (or T-) phase, since it has a lower velocity $(\sim 1.5 \mathrm{~km} / \mathrm{s})$ than crustal seismic phases and thus arrives third on-land seismic stations, after the P- and S-waves (compressional and shear waves, respectively) [Leet et al., 1951; Johnson et al., 1963]. For the vast majority of small-magnitude events, only the T-phase is recorded by hydrophone arrays [Dziak et al., 2004a]. In some cases, for an event with its epicenter close enough to an autonomous hydrophone (typically less than 150/200 km), all the P-, S- and T-phases can be recorded by the instrument. This occurs when the seismic phases traveling through the crust reach the vicinity of the instrument where they are locally converted to acoustic signals.

[4] This paper presents data from, and our analysis of, the north Atlantic hydrophone experiment (called SIRENA which means stands for Seismic Investigation by REcording of Acoustic Waves in 


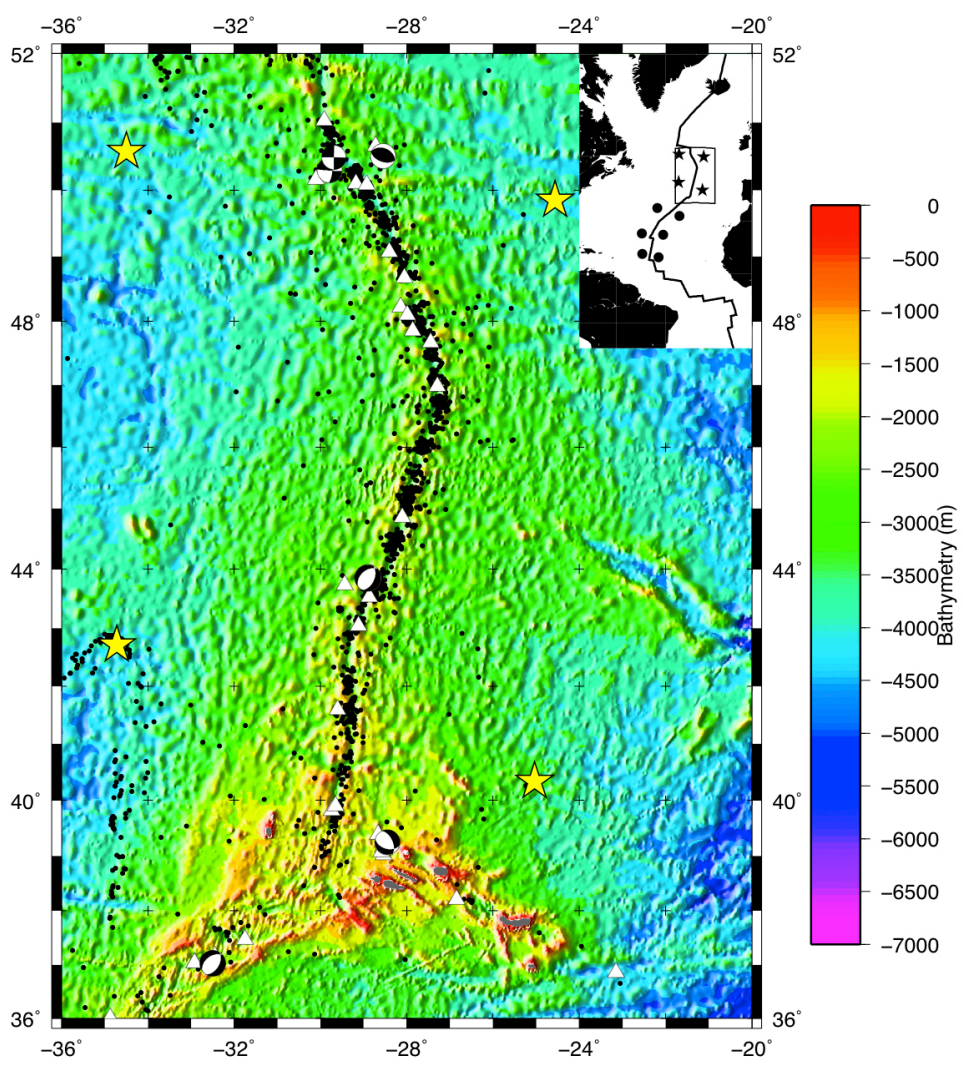

Figure 1. Acoustic events located from June 1, 2002 to September 30, 2003 during the SIRENA experiment. Yellow stars show the positions of the 4 hydrophones used to locate the earthquakes represented by the black dots. White open triangles are the epicenters of the few large magnitude earthquakes listed in the NEIC catalog for the same period. Beach balls are from the Global Centroid Moment Tensor (GCMT) solutions catalog. The inset shows the location of the hydrophones of the SIRENA array (stars) and of the NOAA/PMEL South Azores array (circles).

the North Atlantic). We discuss the spatiotemporal distribution of the seismicity recorded by the SIRENA array along the MAR between $40^{\circ} 20^{\prime} \mathrm{N}$ and $50^{\circ} 30^{\prime} \mathrm{N}$, how these distributions may be related to the large scale influence of the Azores hot spot and how segment scale clusters of events may provide information on seafloor spreading processes.

\section{The SIRENA Experiment}

[5] SIRENA was a France-USA-Portugal cooperative experiment specifically aimed at studying the seismicity of the MAR north of the Azores [Goslin, 2004]. To take full advantage of the SOFAR channel propagation properties and to avoid acoustic shadowing by the Azores Plateau, the autonomous hydrophones were moored north of the Plateau, and on either side of the northern MidAtlantic Ridge between $40^{\circ} 20^{\prime} \mathrm{N}$ and $50^{\circ} 30^{\prime} \mathrm{N}$ (Figure 1). The array was deployed by $R / V L e$ Suroit during a cruise from Ponta Delgada (Azores) to Brest 17 May to 3 June 2002 and was recovered by the RRS Discovery during a cruise from Govan (Scotland) to Ponta Delgada 12 September to 1 October 2003 [Goslin, 2004].

[6] Initially, the SIRENA array was comprised of six instruments, but one hydrophone stopped recording after a week and another was not recovered. Our catalog of events is thus mainly derived from the 4 hydrophones of the SIRENA array, with the addition of two hydrophones deployed by NOAA/PMEL south of the Azores from early 1999 to mid 2005 [Smith et al., 2002] (Figure 1). The seismic events were detected and located with analysis software developed in-house by personnel at the U.S. NOAA/Pacific Marine Environmental Laboratory. The earthquake locations are derived by using the arrival times of the energy maxima of the acoustic signals recorded by at least three of the four instruments. The location software uses a nonlinear regression algorithm to derive an event's 

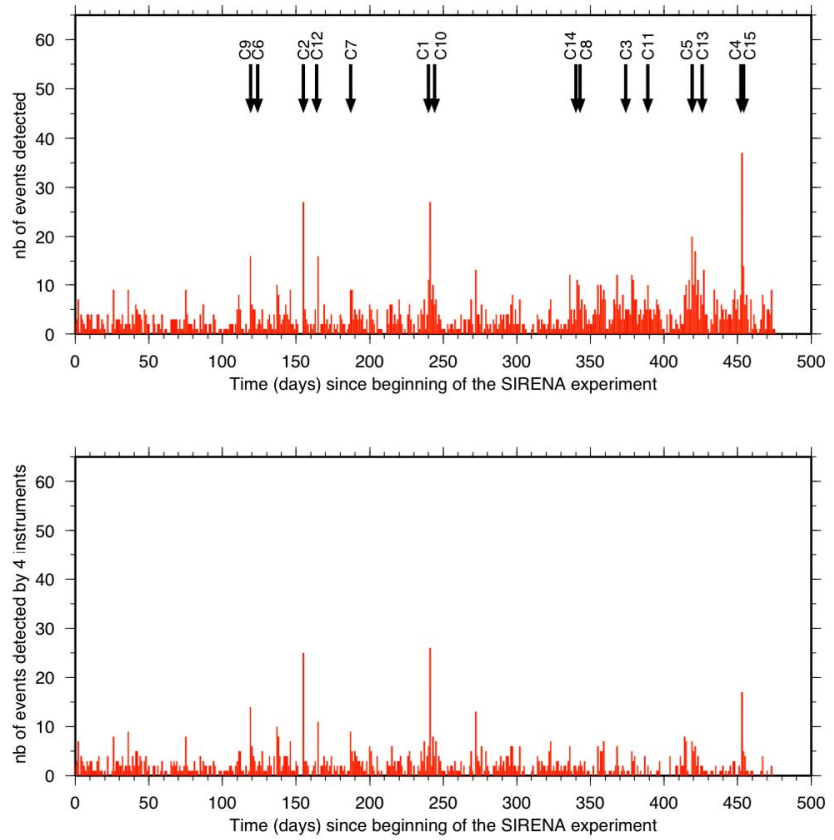

Figure 2. Number of events located inside the SIRENA array as a function of time since the completion of the deployment (i.e. when all the SIRENA array instruments started recording acoustic signals). (top) Daily seismicity rates from the catalog. The vertical arrows show the date of the clusters listed in Table 1. (bottom) Daily seismicity rates derived from the sub-catalog limited to the events detected and localized by four instruments.

latitude, longitude and origin time, where the error in locations is provided by the output of the co-variance matrix [Fox et al., 2001]. The "epicenter" derived in this manner is the point at which the acoustic waves enter the sound channel after they have been converted from seismic waves at the seafloor-ocean interface. Moreover, because our hydroacoustic location technique utilizes oceanographic sound velocity models, which are well known and adjusted for seasonal variations, and our array geometry provides good azimuthal coverage of the MAR, the magnitude of completeness for hydroacoustic arrays is expected to be an order of magnitude lower than what can be achieved using regional or teleseismic earthquake monitoring. In remote areas from land-based network, the locations of earthquakes recorded by four or more hydrophones are generally more accurate than landbased derived locations [Bohnenstiehl and Tolstoy, 2003; Pan and Dziewonski, 2005]; added to a lower detection threshold, hydrophone arrays are thus fully suitable for detailed studies of the low-level seismicity.

[7] The SIRENA catalog lists almost 6000 events, nearly 1700 of which occurred inside the array during its 16 month deployment (1 June 2002 to 19
September 2003). It should be noted that, for the same area and time period, only 19 earthquakes are listed in the National Earthquake Information Center (NEIC) catalog. The SIRENA array thus increases by more than 70-fold the detection and localization of MAR earthquakes north of the Azores. Between 1 June 2002 and 2 May 2003, we also incorporated the northernmost hydrophones deployed by NOAA/ PMEL south of the Azores. These two hydrophones south of the Azores were used only in a complementary role to derive the SIRENA earthquake catalog, with nearly all of the events being located using three or more SIRENA array hydrophones.

[8] The long-term temporal distribution of events, as derived from the SIRENA catalog are shown in Figure 2. The top histogram shows that the mean seismicity rate derived from the catalog remained fairly constant throughout the duration of the SIRENA experiment until day $\sim 340$, after which the seismicity rate increases from 2.8 to 5.2 events/day. This increase in earthquake rate may be due to increased crustal stress that occurred from 7 May through August 2003 with the occurrence of four $M_{w}>5.0$ earthquakes (Table 1). As noted above, the SIRENA catalog was obtained by simultaneously processing the data from the 
Table 1. Clusters Detected Inside the SIRENA Array With the Coordinates of the Main Shock, Its Date, Time, and SL, the Numbers of Events and Duration in Days ${ }^{a}$

\begin{tabular}{|c|c|c|c|c|c|c|c|c|c|c|}
\hline Cluster & $\begin{array}{l}\text { Lat } \\
\text { (deg) }\end{array}$ & Lon (deg) & Date & Time & $\begin{array}{l}\text { SL } \\
(\mathrm{dB})\end{array}$ & Number & $\begin{array}{l}\text { Duration } \\
\text { (days) }\end{array}$ & Type & $\begin{array}{c}\text { Axis } \\
\text { Location/ } \\
\text { Segment }\end{array}$ & Comments \\
\hline $\mathrm{C} 1$ & 41.568 & -29.435 & 2003-01-27 & $15: 32: 47.1$ & 216 & 25 & 5 & Sw & on/c & $m_{b}=4.7(\mathrm{NEIC})$ \\
\hline $\mathrm{C} 2$ & 41.745 & -29.277 & $2002-11-03$ & $08: 38: 31.5$ & 217 & 24 & 19 & Sw & on $/ \mathrm{c}$ & \\
\hline $\mathrm{C} 3$ & 43.333 & -29.569 & 2003-06-10 & $20: 13: 30.0$ & 215 & 20 & 10 & Sw & off & \\
\hline $\mathrm{C} 4$ & 43.797 & -28.645 & 2003-08-27 & $14: 40: 35.4$ & 237 & 38 & 20 & Ma & on/e & $\begin{array}{c}M_{w}=5.4(\mathrm{GCMT}) \\
m_{b}=4.1(\mathrm{NEIC}) \\
\text { studied by Simão } \\
\text { et al. }[2010]\end{array}$ \\
\hline $\mathrm{C} 5$ & 44.349 & -28.465 & $2003-07-25$ & $03: 46: 55.9$ & 215 & 15 & 40 & Sw & on $/ \mathrm{c}$ & \\
\hline C6 & 44.369 & -28.119 & $2002-10-03$ & $06: 22: 10.3$ & 218 & 20 & 37 & Sw & on $/ \mathrm{c}$ & \\
\hline $\mathrm{C} 7$ & 44.954 & -28.006 & $2002-12-05$ & 01:43:04.0 & 220 & 15 & 32 & Sw & on $/ \mathrm{c}$ & \\
\hline $\mathrm{C} 8$ & 46.112 & -27.577 & $2003-05-10$ & $15: 12: 16.5$ & 216 & 15 & 16 & Sw & on/? & \\
\hline C9 & 47.894 & -27.776 & $2002-09-28$ & $05: 09: 45.3$ & 238 & 48 & 35 & $\mathrm{fMa}$ & on/? & $m_{b}=4.6(\mathrm{NEIC})$ \\
\hline $\mathrm{C} 10$ & 48.656 & -28.195 & 2003-01-31 & $16: 15: 25.7$ & 221 & 28 & 36 & Sw & on/? & \\
\hline C11 & 49.987 & -28.984 & 2003-06-25 & $06: 24: 29.8$ & 216 & 15 & 36 & $\mathrm{Nc}$ & on/? & \\
\hline $\mathrm{C} 12$ & 50.013 & -28.972 & 2002-11-12 & 21:52:54.7 & 220 & 20 & 40 & Sw & on/? & $m_{b}=4.2(\mathrm{NEIC})$ \\
\hline $\mathrm{C} 13$ & 50.263 & -29.085 & 2003-08-01 & $09: 22: 58.5$ & 215 & 17 & 35 & Sw & on/? & \\
\hline $\mathrm{C} 14$ & 50.232 & -29.996 & 2003-05-07 & $13: 10: 21.0$ & 242 & 27 & 36 & Ma & off & $\begin{array}{c}M_{w}=5.1(\mathrm{GCMT}) \\
M_{w}=5.0(\mathrm{GCMT})\end{array}$ \\
\hline $\mathrm{C} 15$ & 50.489 & -28.648 & 2003-08-29 & 07:07:17.5 & 234 & 16 & 2 & Ma & off & $\begin{array}{c}M_{w}=5.2(\mathrm{GCMT}) \\
m_{b}=4.4(\mathrm{NEIC})\end{array}$ \\
\hline
\end{tabular}

${ }^{\mathrm{a}}$ Following Mogi [1963] and Sykes [1970] classification, clusters are sorted in 3-types: Sw for swarm, Ma for main shock-aftershock sequence, fMa for foreshock-main shock-aftershock sequence, and Nc for unclassified type. Cluster location are denoted off for an off-axis location and on for an on-axis location. In the latter case, the location of the cluster in the segment is noted $c$ for a center location, $e$ for an end-segment location and ? for an undetermined location. The $M_{w}$ magnitude from the GCMT catalog, or if not available, the $m_{b}$ from the NEIC catalog are given.

SIRENA and the South Azores arrays. The recovery of the southern array in March 2003 explains the decrease in the rate of events (from 2.4 to 1.6 events/day) after day 334 .

\section{Methods}

[9] A total of 1696 earthquakes were located within the SIRENA array during 16 months recording period; 1013 events were located using 4 hydrophones or more. We estimated the magnitude of completeness of our event catalog and derived location errors for all events. These values were then used in our review of the space-time distribution of the seismicity and as the basis for our earthquake cluster analysis.

\subsection{Source Level and Magnitude of Completeness}

[10] Our estimate of the source Level of completeness $\left(\mathrm{SL}_{c}\right)$ for the SIRENA catalog was limited to the events located inside the array and is needed to assess the earthquake cluster search. The $\mathrm{SL}_{c}$ is the minimum value of the source level at which the logarithm of cumulative number of events having a given SL departs from a linear relationship. The $\mathrm{SL}_{c}$ is similar to the magnitude of completeness $M_{c}$ computed from fitting the Gutenberg-Richter law to a seismically derived earthquake catalog:

$$
\log (N)=a_{t}+b_{t} \mathrm{SL}
$$

where $N$ is the number of events having a size equal to or greater than SL, $a_{t}$ is a constant dependent on the total number of events and $b_{t}$ is representative of the frequency-size distribution [Bohnenstiehl et al., 2002].

[11] $\mathrm{SL}_{c}$ 's were computed from the catalog for the MAR events within two-degree boxes of latitude between $40^{\circ} 30^{\prime} \mathrm{N}$ and $50^{\circ} 30^{\prime} \mathrm{N}$. These $\mathrm{SL}_{c}$ 's range from $206 \mathrm{~dB}$ to $210 \mathrm{~dB}$, with a mean of $207.8 \mathrm{~dB}$. The narrow range of $\mathrm{SL}_{c}$ 's allows us to rule out possible detection biases of the SIRENA array which could be due to the presence of shallow bathymetry along the propagation path between the earthquake source and hydrophones. Relationships between source levels and magnitudes are difficult to assess. Only empirical relations have yet been proposed [Dziak et al., 2004a], based on simultaneous observation of large earthquakes by landstations and hydrophone arrays. The magnitude of completeness $M_{c}$ of the hydrophone array can then 

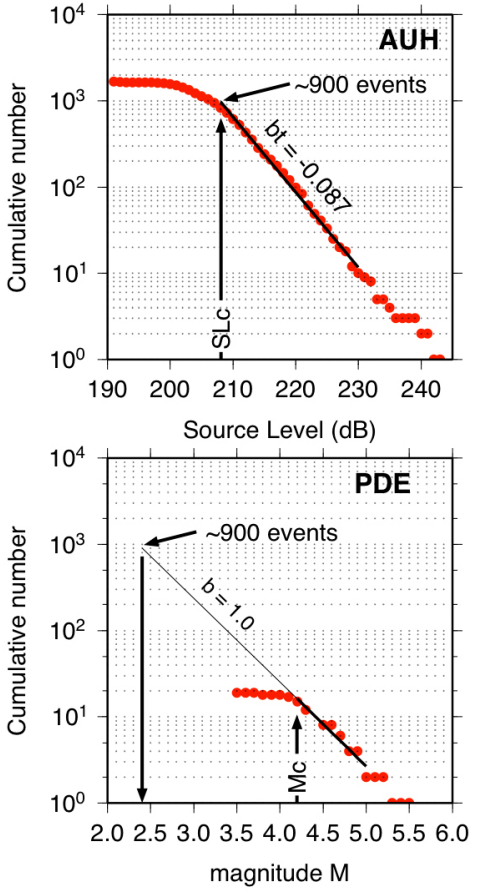

Figure 3. (top) Logarithm of the cumulative number of events from the SIRENA AUH catalog plotted versus Source Level (SL). The Source Level of completeness $\mathrm{SL}_{c}$ is defined as the minimum SL where the distribution of the cumulative number of events departs from the linear Gutenberg-Richter law (shown as a black line). $\mathrm{SL}_{c}$ equals $\sim 208 \mathrm{~dB}$ and corresponds to $\sim 900$ events. Least squares regression estimate of the slope of the data $\left(b_{t}\right)$ is 0.087 between 208 and $230 \mathrm{~dB}$. Data with SL > $230 \mathrm{~dB}$ are excluded due to the clipping of the hydrophone sensors. (bottom) Logarithm of the cumulative number of events from the National Earthquake Information Center's (NEIC) Preliminary Determination of Epicenters (PDE) catalog detected within the SIRENA array during the SIRENA deployment plotted versus their $\mathrm{m}_{b}$ magnitude. The magnitude of completeness $\left(M_{c}\right)$ is the minimum magnitude where the distribution of the cumulative number of events departs from the linear Gutenberg-Richter law (shown as a black line); $M_{c}$ is equal to 4.2. A $b$-value of 1.0 is obtained by least squares regression of data. Extrapolating the linear trend of the Gutenberg-Richter law toward smaller magnitudes, yields a $M_{c} \sim 2.4$ corresponding to the $\sim 900$ events, number of events detected at the $\mathrm{SL}_{c}$. It means that the threshold detection of the SIRENA array is in the order of $m_{b} \sim 2.4$.

be evaluated as follows. First the source level of completeness for the SIRENA array is derived from Figure 3 and equals $\sim 208 \mathrm{~dB}$ and corresponds to $\sim 900$ events detected within the array during its deployment. Second, the linear fit between the cumulative number of events and their magnitude is extrapolated toward smaller magnitudes (Figure 3, bottom). This line intersects the 900 -event horizontal line close to a magnitude $m_{b}$ value of 2.4, which we consider to be the magnitude of completeness $M_{c}$ or essentially the detection threshold of the SIRENA array.

\subsection{Location Error Distribution}

[12] To interpret a distribution of seismic events with respect to accurately mapped bathymetric features or faults, their uncertainties in time and in location need to be assessed. These errors can be computed only using four or more hydrophones. Histograms in Figure 4 show that $90 \%$ of the events inside the array have an error in origin time lower than 1 second and latitudinal and longitudinal errors less than $\sim 2 \mathrm{~km}$. These results confirm that the hydroacoustic technique can be successfully used for detailed seismicity studies of mid-oceanic ridges.

\subsection{Earthquake Cluster Identification}

[13] Cluster analyses provide many useful insights on processes occurring along mid-oceanic ridges, for instance to distinguish tectonic events with main shock-aftershock sequence from non-tectonic, possibly magmatic, sequences [e.g., Bohnenstiehl et al., 2002; Simão et al., 2010].

[14] In order to delineate clusters, we adapted the program "cluster" included in the seismic analysis SEISAN package [Haskov and Ottemoller, 2008] to the acoustic magnitude or SL. A minimum SL of $215 \mathrm{~dB}$ was chosen as the minimum value of possible main shocks. The cluster was then defined as including all events that occurred within 40 days after and 1 day before these main shocks and located within a radius of $30 \mathrm{~km}$ from the main shock. Thirty kilometers was chosen because it corresponds to the maximum fault length expected in a slow-rate spreading ridge environment [Bohnenstiehl and Kleinrock, 2000]. The time window of forty days after the main shock corresponds to the greater time window observed in previous studies on the MAR [Bohnenstiehl et al., 2002; Simão et al., 2010]. Our analysis is limited to the clusters having 15 events. Fifteen clusters were thus detected along the MAR between $40^{\circ} \mathrm{N}$ and $51^{\circ} \mathrm{N}$ during the SIRENA deployment (Table 1), with the maximum number of earthquakes in a swarm being 48 events. Among the 19 earthquakes listed by the NEIC catalog during the SIRENA experiment, 

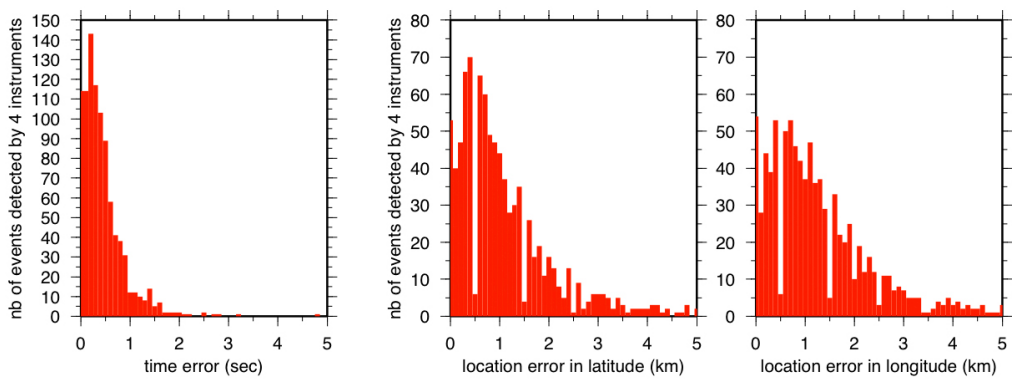

Figure 4. Histograms (left) of time errors in origin time and of location errors in (middle) latitude and (right) longitude of the events located within the SIRENA array. Errors are computed only for the events detected by the four instruments.

we detected 9 clusters associated with these large earthquakes. The 10 remaining events from the NEIC catalog are isolated in time and space in the SIRENA catalog and therefore do not appear as being part of a sequence.

\subsection{Temporal Distribution of the Clusters and Modified Omori Law}

[15] The patterns of earthquake clusters were classified into the following three types [Mogi, 1963];

(1) A large earthquake followed by aftershocks, (2) large earthquakes preceded by foreshocks and

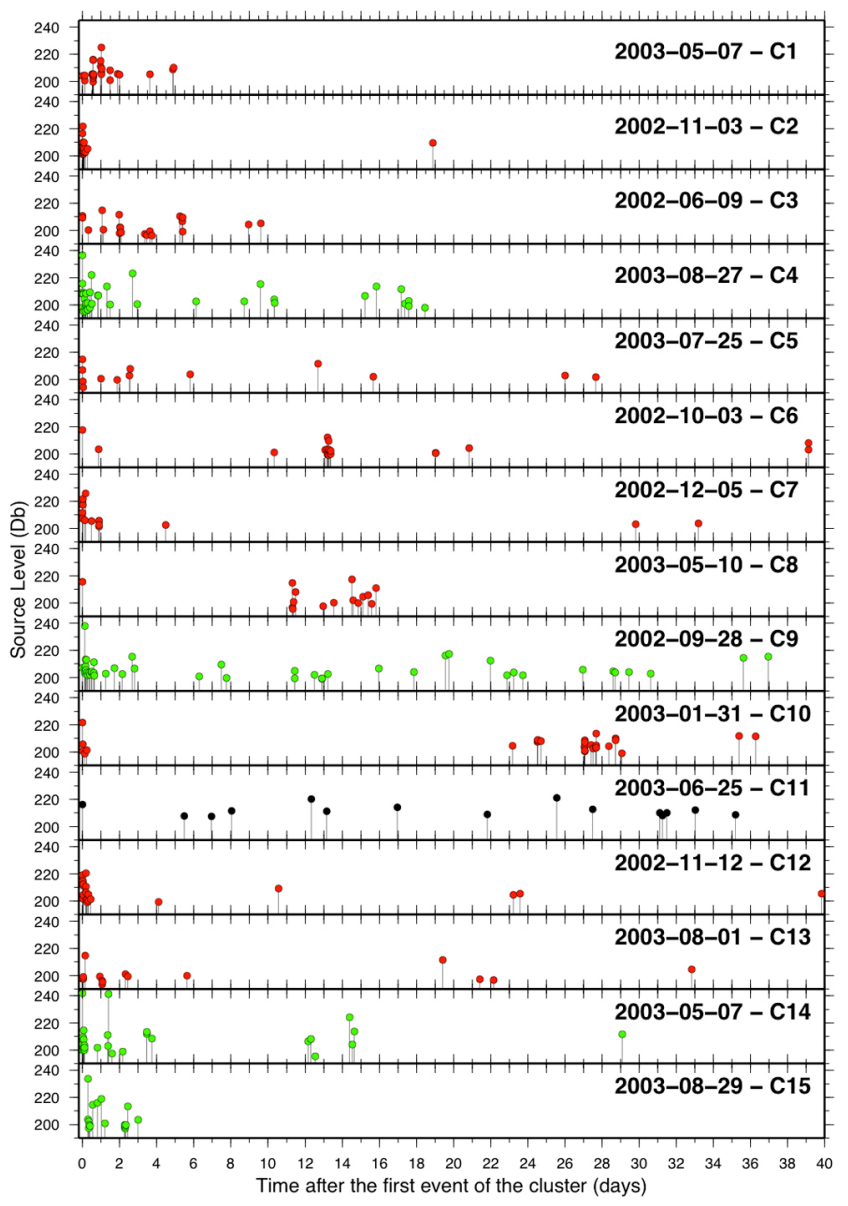

Figure 5. Source level versus time relative to the main shock for clusters including 15 or more events. The color of circles reflects the processes which generated the clusters: green for a main shock-aftershock or fore-main-aftershock sequence, red for swarms and black for an unclassified cluster following Mogi [1963] and Sykes [1970]. 

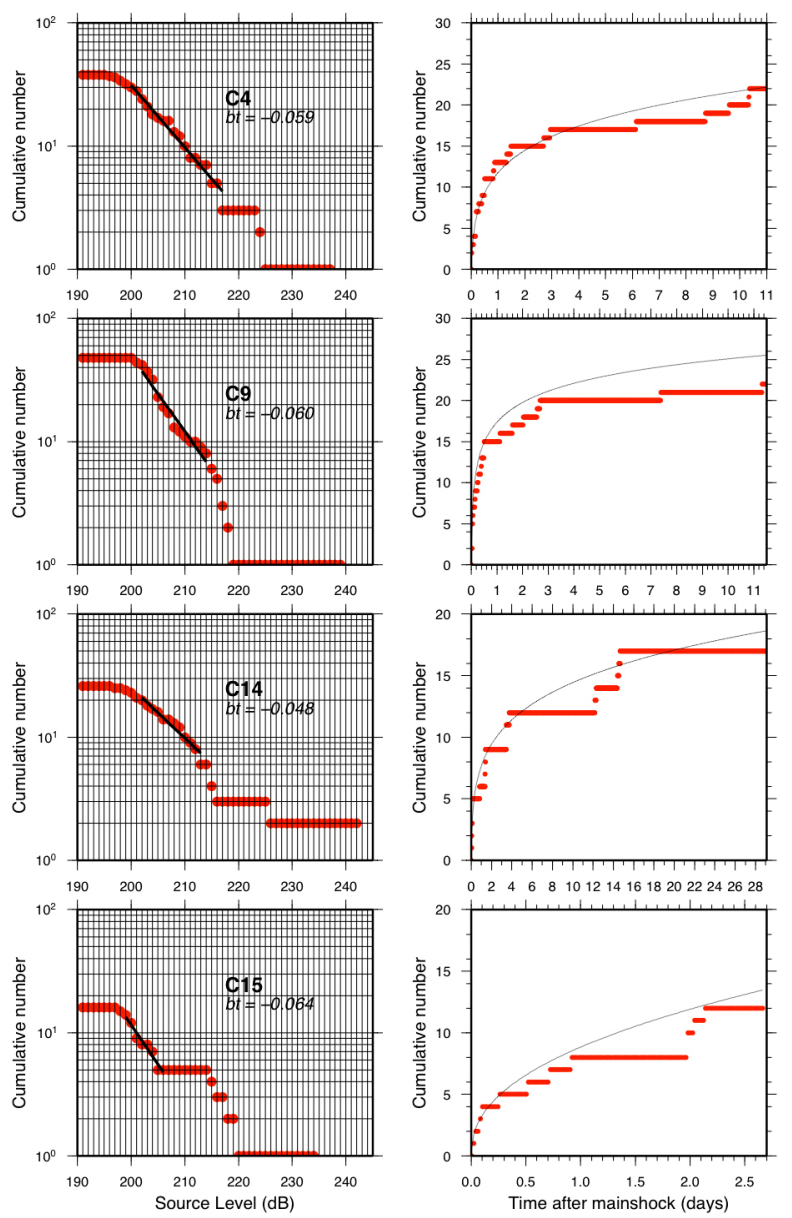

Figure 6. (left) Cumulative-number of events above a given source level (SL) versus the source level and (right) the cumulative number of events versus time after the main shock, for sequences $C 4, C 9, C 14$ and $C 15$. An $\mathrm{SL}_{c}$ value of $202 \mathrm{~dB}$ is obtained for $C 9$ and $C 14$, a value of $200 \mathrm{~dB}$ for $C 4$ and a value of $199 \mathrm{~dB}$ for $C 15$. The $b_{t}$ value is indicated on each plot. Events with a $\mathrm{SL} \leq 199$, 200 or $202 \mathrm{~dB}$ and $\mathrm{SL}_{c}>230 \mathrm{~dB}$ were excluded from the MOL fitting and parameter computations. The solid line in Figure 6 (right) is the predicted cumulative distribution for the maximum likelihood estimates of the MOL parameters reported in Table 2. Red lines and circles are the data.

followed by aftershocks and (3) earthquake swarms with events of roughly equivalent magnitude but do not show a dominant earthquake. The type (1) and (2) clusters were attributed to slip on transform faults, and are likely of tectonic origin. In an analysis of magnitude versus time distribution of large earthquakes along the East Pacific Rise (EPR) and the MAR, Sykes [1970] interpreted the type (3) swarm as precursors of volcanic eruptions or as seismic activity related to magmatic processes that did not reach the surface and for which fault activation is a response to magma emplacement into the shallow crust. This cluster classification proved very useful for further analyses of Ocean Bottom Seismometer data [Tolstoy et al., 2001] or hydrophone array data [Bohnenstiehl et al., 2002; Dziak et al., 2004b, 2009; Simão et al., 2010].

[16] We next analyzed the SL variation with time distribution of each cluster (Figure 5). Among the fifteen identified clusters, three fit a typical a main shock-aftershock distribution, one fit a foreshockmain shock-aftershock style of sequence, ten clusters reflect a swarm type and one cluster could not be classified (Table 1). All the identified sequences include a dominant earthquake $(\mathrm{SL}>=230 \mathrm{~dB})$ with a more or less rapid SL decrease in time. The events of the swarm sequences are concentrated over a short period (less than 10 days) with similar moderate to low SLs (all below $230 \mathrm{~dB}$ ) and without a dominant SL. Last, the only cluster that does not fit into our classification shows constant activity during the 40 day time window with no single large event.

[17] A validation of the main shock-aftershock sequence can be performed by matching the cumulative number of events versus time and fitting a Modified Omori Law (MOL) [Ogata, 1983; Utsu, 1995]. Events following such a main shockaftershock distribution generally occur in a tectonic context. Events are considered as aftershocks if the frequency per unit time $n(t)$ follow a MOL within a time interval $[S, T]$ :

$$
n(t)=K(c+t)^{-p}
$$

where $K, c$ and $p$ are empirically derived constants, $\mathrm{T}$ is the duration of the sequence and $T \min =0$ corresponds to the time of the main shock. These parameters are estimated using the method of maximum likelihood carried out within the software package SAseis using a Fletcher-Powell optimization procedure [Utsu and Ogata, 1997]. To evaluate the goodness-of-fit, we compute the AndersonDarling statistic $\left(A^{2}\right)$. The values of $A^{2}$ less than 1 indicate that a sequence's distribution of aftershocks with time can be adequately fitted by a MOL. It may be difficult to identify the aftershock in the main shock coda and because of their complicated nature in the initial stage. To avoid this bias, Tmin is found to best fit to the data in the [Tmin, Tmax] time interval. $\mathrm{A} \mathrm{SL}_{c}$ is determined for each individual sequence and aftershocks with $\mathrm{SL}<=\mathrm{SL}_{c}$ are removed before calculating the MOL parameters [Bohnenstiehl et al., 2002]. 
Table 2. Properties of Aftershock Sequences ${ }^{\mathrm{a}}$

\begin{tabular}{|c|c|c|c|c|c|c|c|}
\hline Sequence & [Tmin, Tmax] & $\mathrm{N}$ & $\mathrm{p}$ & c (days) & $\mathrm{K}$ & AIC & $A^{2}$ \\
\hline \multirow[t]{3}{*}{$\mathrm{C} 4$} & {$[0.002,17.6]$} & 28 & $0.74(0.10)$ & $0.000(0.005)$ & $3.80(0.76)$ & -16 & 1.50 \\
\hline & {$[0.002,11.0]$} & 22 & $0.89(0.21)$ & $0.024(0.050)$ & $3.82(1.08)$ & -20 & 0.61 \\
\hline & {$[0.002,3.0]$} & 17 & $0.91(0.39)$ & $0.035(0.085)$ & $4.19(1.33)$ & -38 & 0.30 \\
\hline \multirow[t]{3}{*}{ C9 } & {$[0.005,36.9]$} & 39 & $0.75(0.09)$ & $0.000(0.019)$ & $4.46(0.90)$ & 5 & 1.90 \\
\hline & {$[0.005,11.5]$} & 24 & $1.05(0.18)$ & $0.013(0.025)$ & $3.57(0.90)$ & -55 & 0.42 \\
\hline & {$[0.005,3.0]$} & 17 & $0.91(0.39)$ & $0.001(0.010)$ & $4.35(1.28)$ & -70 & 0.31 \\
\hline \multirow[t]{3}{*}{$\mathrm{C} 14$} & {$[0.007,29.1]$} & 19 & $0.82(0.16)$ & $0.008(0.039)$ & $2.39(0.76)$ & 13 & 0.69 \\
\hline & {$[0.007,1.39]$} & 9 & $0.86(0.60)$ & $0.012(0.071)$ & $2.36(1.47)$ & -23 & 2.10 \\
\hline & {$[1.39,29.1]$} & 10 & $0.73(1.00)$ & $0.000(7.013)$ & $1.94(5.81)$ & 42 & 1.34 \\
\hline $\mathrm{C} 15$ & {$[0.002,2.7]$} & 13 & $0.57(0.22)$ & $0.000(0.012)$ & $3.80(1.23)$ & -17 & 0.93 \\
\hline
\end{tabular}

${ }^{\mathrm{a}}$ The time interval [Tmin, Tmax] in days is relative to the main shock during which the data are modeled. $\mathrm{N}$ is the number of aftershocks within this interval used in determining $\mathrm{p}, \mathrm{c}$ and K. $A^{2}$ is the Anderson-Darling statistic. The sequences with $A^{2} \approx 1$ are well fit by the MOL model.

[18] Special attention was given to four sequences with a high SL value for the main shock: $C 4, C 9$, $C 14$ and $C 15$ (fMa or Ma type in Table 1). The SLc is estimated to be $202 \mathrm{~dB}$ for $\mathrm{C} 9$ and $\mathrm{C} 14$ sequences, $200 \mathrm{~dB}$, for $\mathrm{C} 4$ sequence and $199 \mathrm{~dB}$ for $\mathrm{C} 15$ (Figure 6). Calculations for each sequence over the whole time interval yields $A^{2}$ values that fit the MOL for $C 14$ and $C 15$. A good fit of the MOL for the $C 4$ and $C 9$ sequences is obtained at shorter time intervals (Table 2 and Figure 6). For these two sequences, we search for the largest time interval with $A^{2}$ values below 1 and the MOL parameters for the best $A^{2}$ value (Table 2). The C14 sequence shows a second high SL event after the first main shock (Figure 6), with both the main shock and first large aftershock listed in the Global Centroid Moment Tensor (GCMT) catalog with equivalent $M_{w}$. We attempted to fit individually a MOL for these two main shocks, but the high values of $A^{2}$ (Table 2) suggest that these sequences do not follow a MOL.

\section{North Azores Seismicity}

[19] We present in this section the seismicity observed inside the array from $40^{\circ}$ to $52^{\circ} \mathrm{N}$ and $25^{\circ}$ to $33^{\circ} \mathrm{W}$ at the large-scale to investigate the thermal state of the lithosphere and at segment-scale to analyze spreading center processes. We propose that the along-ridge seismicity distribution has a combined origin of (1) a large-scale trend reflecting large-scale variations of the thermal state of the MAR axis resulting from a variable along-ridge influence of the Azores hot spot [e.g., Goslin et al., 1998]; (2) short-scale variations due to more local seismogenic processes which are considered to be mainly dependent on intrasegment variations of the thermal state of the ridge axis, such as those observed by Kuo and Forsyth [1988], Lin et al.
[1990] and Thibaud et al. [1998] and also modeled by Gac et al. [2003].

\subsection{Large-Scale MAR's Seismicity Distribution}

[20] Figure 7 shows all earthquakes from the SIRENA catalog between $40^{\circ} \mathrm{N}$ and $51^{\circ} \mathrm{N}$ superimposed on a bathymetric map. Scattered seismicity is observed between latitudes $40^{\circ} \mathrm{N}$ and $43^{\circ} 30^{\prime} \mathrm{N}$. Conversely, north of $43^{\circ} 30^{\prime} \mathrm{N}$, the events are generally more tightly grouped although not necessarily constituting clusters. In order to distinguish between the large-scale trend of the seismicity and seafloor spreading processes generating seismic clusters, the SIRENA catalog was declustered, meaning we removed events belonging to the 15 clusters from the catalog. Figure 8 displays the latitudinal distribution of the seismicity rate, derived from the total and from the declustered SIRENA catalogs.

[21] The declustered seismicity rate versus latitude, summed for the total duration of the SIRENA experiment, shows two characteristic trends: (1) the seismicity rate increases with latitude, that is with increasing distance away from the Azores hot spot. Such a trend is consistent with the existence of an along-ridge hot spot influence on the MAR upper mantle and crustal regime, and (2) in addition to this first-order trend, the seismicity rate shows a distinctive step near $43^{\circ} \mathrm{N}$, increasing drastically from an average of $\sim 76$ events, from $40^{\circ} 30^{\prime} \mathrm{N}$ to $43^{\circ} \mathrm{N}$, to an average of 142 (or almost double) from $43^{\circ} \mathrm{N}$ to $50^{\circ} \mathrm{N}$ (Figure 8). This evidence would set the northernmost limit of the along-ridge influence of the Azores hot spot in the relay zone located near $43^{\circ} 30^{\prime} \mathrm{N}$, as initially proposed by Goslin et al. [1998] from an interpretation of the along-ridge distribution of upper mantle velocities and Sr isotope data. Analyzing the declustered catalog is further warranted by the strongly variable contribution 

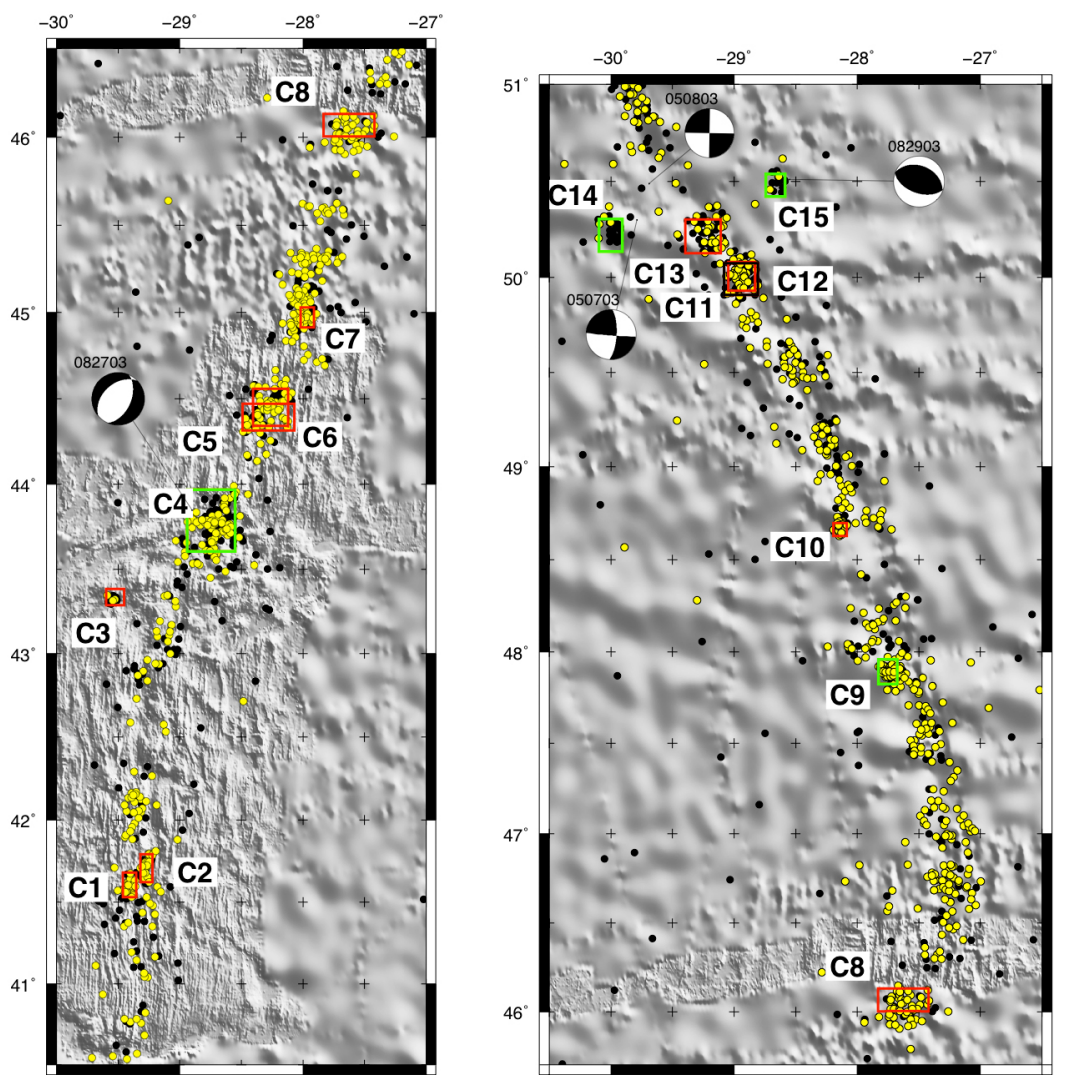

Figure 7. Composite bathymetric map combining the ETOPO1 grid and the high-resolution TRIATNORD multibeam bathymetric grid [Goslin et al., 1999] between $40^{\circ}$ and $45^{\circ} \mathrm{N}$. Circles show earthquakes located with 4 or more hydrophones (yellow) and with 3 hydrophones (black). All the identified cluster (Table 1) are indexed from South (C1) to North (C15). Available focal mechanism solutions from the GCMT catalog are also shown. The boxes encompass the events of each cluster, their color are relative to their cluster classification (Figure 5 and Table 1).

of the clusters to the total seismicity rate with latitude, below and above $43^{\circ} 30^{\prime} \mathrm{N}$. There are 12 clusters, comprising 257 events, that occurred north of $43^{\circ} 30^{\prime} \mathrm{N}$, while 3 clusters totaling 69 events occurred south of $43^{\circ} 30^{\prime} \mathrm{N}$. A cluster including a large number of events $(C 4)$ is located near $43^{\circ} 30 \mathrm{~N}$ within the relay zone itself [Maia et al., 2007].

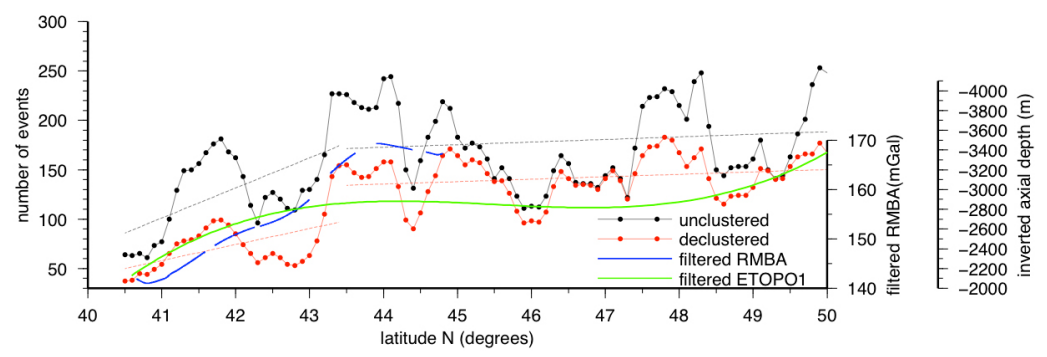

Figure 8. Number of events detected by the SIRENA array as a function of latitude. Both curves are obtained by calculating the cumulative number of events within a $1^{\circ}$ latitudinal window, moving by steps of $0.1^{\circ}$. The black upper curve is computed from the full SIRENA catalog, the red lower curve represents the seismicity derived from the declustered catalog. We computed linear trends by least squares regression for the two curves, both present a positive slope, with a higher factor for the trend of the declustered curve. The blue line shows the filtered Residual Mantle Bouguer Anomaly (RMBA), corresponding to the MBA after the removal of the gravity effect of a cooling lithosphere, computed by Maia et al. [2007] from $40.7^{\circ} \mathrm{N}$ to $44.8^{\circ} \mathrm{N}$. The green line shows, in an inverted scale, the overall trend of the axial depth filtered from the ETOPO1 grid [Amante and Eakins, 2009]. 

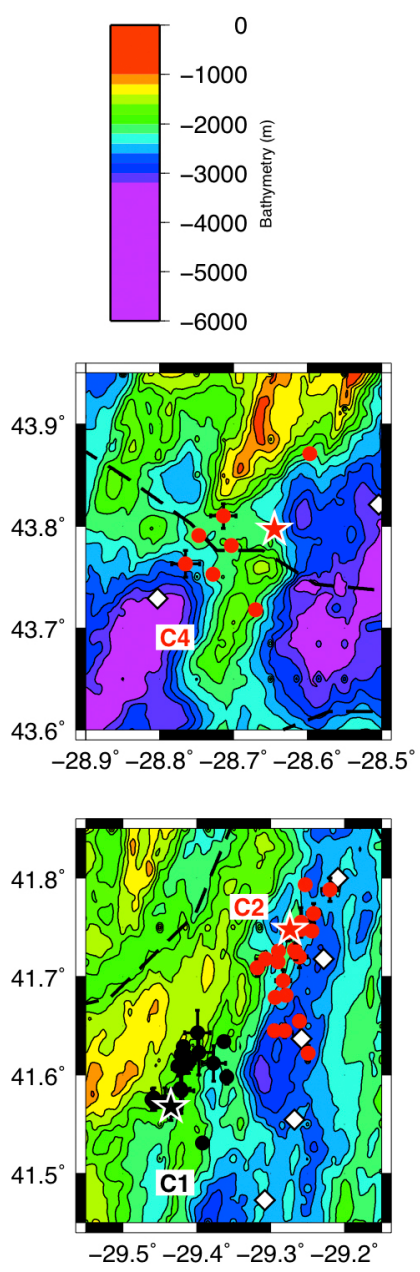
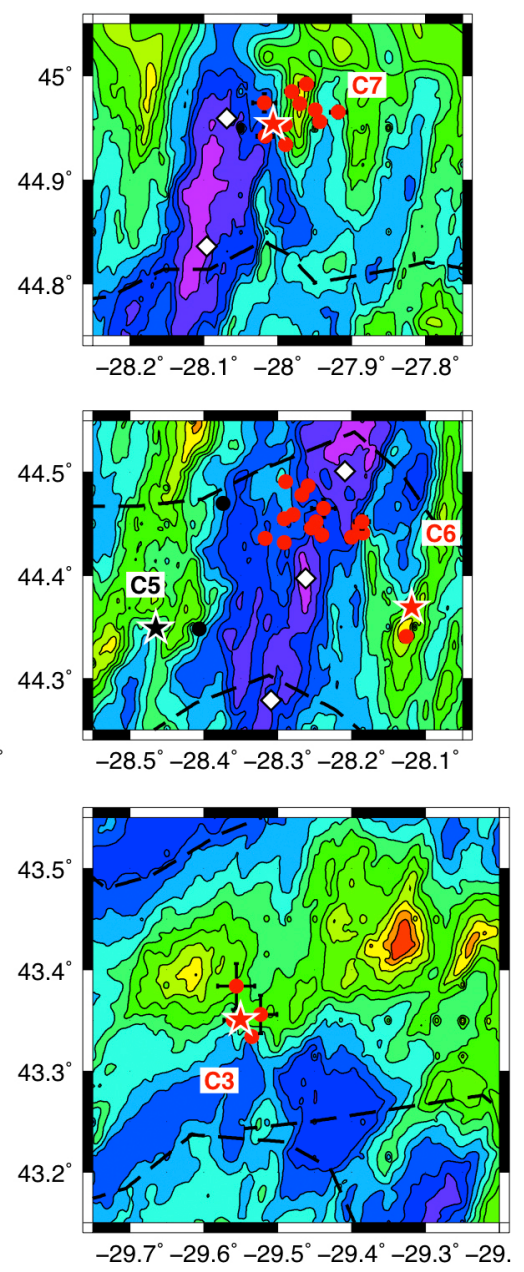

Figure 9. Selection of earthquakes superimposed on the TRIATNORD bathymetric map [Goslin et al., 1999]. Only earthquakes detected by four hydrophones with latitude and longitude errors smaller than $2.5 \mathrm{~km}$ are shown on the map. The red or black stars show the position of the larger earthquakes (main shock) of each sequence resulting from the cluster search and circles of the corresponding color, the subsequent events (aftershocks). Errors bars are shown for all events. Segments boundaries identified by Maia et al. [2007] are shown by the black dashed lines. The white diamonds show the locations of the ridge axis deduced from magnetic anomalies [Maia et al., 2007].

[22] This large-scale trend of seismicity, despite the short 16-month duration of the SIRENA experiment, can be interpreted as an effect of the Azores hot spot and can be compared to other observations, such as gravity. For instance, the Residual Mantle Bouguer Anomaly (RMBA) which corresponds to the MBA after removal of the gravity effect due to the cooling of the lithosphere is interpreted in terms of anomalous crustal thickness variations and/or mantle thermal structures [Kuo and Forsyth, 1988]. Maia et al. [2007] computed the RMBA along the MAR from $40^{\circ} 42^{\prime} \mathrm{N}$ to $44^{\circ} 48^{\prime} \mathrm{N}$ using the method of Rommevaux et al. [1994]: the RMBA displays a similar trend with an important increase from $40^{\circ} 42^{\prime} \mathrm{N}$ to $43^{\circ} 30^{\prime} \mathrm{N}$, followed by a constant and positive value around $10 \mathrm{mGal}$ up to $44^{\circ} 48^{\prime} \mathrm{N}$ (blue dashed line on Figure 8). Maia et al. [2007] interpreted this change at $43^{\circ} 30^{\prime} \mathrm{N}$ as an effect of a thicker and warmer crust underneath the relay zone, which is consistent with the increasing number of earthquakes up to this zone. Thus the Sr isotope, mantle seismic velocities, RMBA, seismicity rate data all indicate the northern limit of the Azores plume influence is at $43^{\circ} 30^{\prime} \mathrm{N}$.

\subsection{Spatial Distributions of Earthquakes at Segment Scales}

[23] During the 16 months hydroacoustic observations of the SIRENA array, we found 15 clusters with more than 15 events. In their analysis, Simão et al. [2010] found only one cluster based on a threshold of 40 events. Most single events and clusters are located along the ridge-axis. However, 


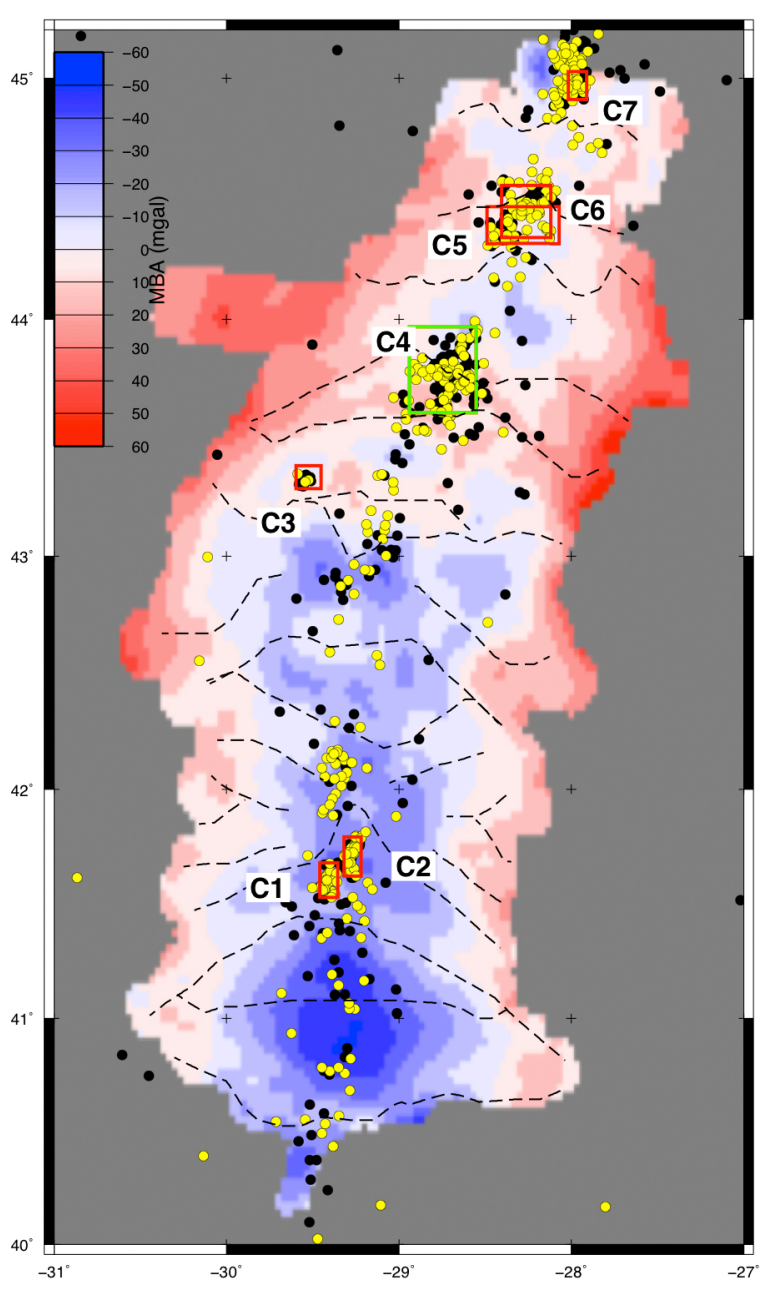

Figure 10. Earthquake locations superimposed on the Mantle Bouguer Anomaly (MBA) [Maia et al., 2007]. Circles show earthquakes located with 4 or more hydrophones (yellow) and with 3 hydrophones (black). The tectonic cluster (green box) is located in a region with the highest MBA values, whereas magmatic swarms (red boxes) are located in areas with low MBA values (Figure 5 and Table 1).

there is also a significant amount of seismicity off the ridge-axis (Figure 7) including three clusters. We note that most of the scattered off-axis events were located using only 3 hydrophones.

\subsubsection{Sequences Located Off-Axis}

[24] The three off-axis sequences are $C 3, C 14$ and $C 15$. The $C 14$ and $C 15$ sequences are located close to $50^{\circ} 30^{\prime} \mathrm{N}$ on both sides of the axial valley. The GCMT solutions indicate a strike-slip mechanism in the $C 14$ sequence and a compressive mechanism in the $C 15$ one (Figure 7). As both $C 14$ and $C 15$ clusters were considered above as tectonic sequences, the $C 14$ sequence could be due to the reactivation of a fracture zone [DeLong et al., 1977; Wiens and Stein, 1984] and the C15 or activity along an inside corner transform [Engeln et al., 1986] or due to a thrust fault previously observed by Galindo-Zaldivar et al. [2000] on multichannel seismic profiles. As mentioned above, the $C 3$ swarm shows a magmatic type of distribution in time. The spatial distribution of the events is concentrated in a small $7 \times 7 \mathrm{~km}$ area. If this seismic activity is truly magmatic in origin, then it implies magmatic activity can occur up to $50 \mathrm{~km}$ off-axis, a surprising observation along a slow-spreading ridge. Aside from scattered events, the off-axis seismic activity is restricted to these three swarms.

\subsubsection{Sequences Located On-Axis}

[25] Swarms of earthquakes recorded on 4 hydrophones and located between $40^{\circ} \mathrm{N}$ and $45^{\circ} \mathrm{N}$ with location errors smaller than $2.5 \mathrm{~km}$ are plotted on the TRIATNORD bathymetric map [Goslin et al., 1999; Maia et al., 2007] (Figure 9). In this latitudinal range, seven swarms were identified.

[26] Among these sequences, only the $C 4$ sequence fits a MOL (Figure 6 and Table 2), indicative of a tectonic-type sequence. The region of the $C 4$ sequence has the highest seismic rates with 0.29 earthquake/day (consistent with similar rates near $22.5^{\circ} \mathrm{N}$ of the MAR [Smith et al., 2002]) and nearly continuous seismic activity during the SIRENA experiment. It is located at the end of a spreading segment in a relay zone where the gravimetric crust is thin and peridotites were sampled [Maia et al., 2007], corresponding probably to a non-transform discontinuity. The spatial distribution of the events on the map may reflect the projection at the seafloor surface of aftershocks located on a dipping fault plane. The $C 4$ sequence probably represents a tectonic episode that lasted 11 days (Table 2), however we are unsure we recorded the whole sequence because it began 23 days before the end of the SIRENA experiment. The intrusion of a magma dike at the same time as the tectonic episode has also been proposed by Simão et al. [2010] for this sequence. As only 8 events were detected by four hydrophones (Figure 9), it is difficult to conclude with any certainty that migration of earthquakes associated with magma intrusion occurred. We derived a $p$ value of 1 (Table 2) for this sequence which indicates a slow decay rate. Thus the $C 4$ sequence may be the result of the activation of a fault within relatively cold lithosphere. The apparent spatial distribution of the aftershocks along a 
dipping fault plane and the presence of peridotites indicate this area is a detachment fault, similar to those observed by Cann et al. [1997] which allows exhumation of mantle rocks [Cannat, 1993, 1996; Ildefonse et al., 2007].

[27] $C 1$ and $C 2$ swarms are located near the center of Segment 3 as identified by Maia et al. [2007]. Swarm $C 2$ occurred on an active volcanic ridge, consistent with a magmatic character for these two sequences. $\mathrm{C} 1$ is located on the western wall of the rift valley. Normally this location indicates a tectonic origin for the events, however Cannat et al. [1995] observed a volcanic cone on the western ridge flank near the Lucky Strike segment. Neither of these two sequences appeared to propagate in space and time. However, $C 2$ swarm occurred in November 2002 approximately $10 \mathrm{~km}$ north of $C 1$, which occurred three months later. The occurrence of $C 2$ may have triggered $C 1$ by changing pressure within the magma source reservoir, a process which has been recently documented in subaerial volcanoes in rift-zones-[e.g., Baer et al., 2008; Albaric et al., 2010]. The same spatial distribution on one of the ridge flanks is observed for $C 7$ swarm.

[28] The C6 sequence, located in the center of Segment 10 [Maia et al., 2007], shows a different spatial behavior, since the main shock occurred about $10 \mathrm{~km}$ away from the majority of the events that occurred 12 days later (Figure 5). Swarm C5 also occurred in Segment 10 but was located along the Eastern flank. There is a ten month lag between these two swarms; possibly, the stress release during $C 6$ events could have triggered $C 5$ sequence. However, there may also be no spatial and time relationship between these two clusters. The different seismic pattern on both flanks of this segment may be due the presence of a thinner crust under the west flank than under the east flank as evidenced by Maia et al. [2007].

[29] No migration pattern is observed for any of these swarms, but we may have missed all the events with a magnitude lower than our estimated $\mathrm{SL}_{c}$ (2.4). Nevertheless, a possible interpretation for this lack of migration pattern could be the occurrence of multiple vertical magmatic pulses as observed by Tolstoy et al. [2001] along the Gakkel Ridge which is the slowest spreading ridge on the planet. An alternative interpretation could also be a shallow intrusion of magmatic bodies, as imaged by Magde et al. [2000] within a MAR segment.

[30] From the spatial observations of clusters between $40^{\circ} \mathrm{N}$ and $45^{\circ} \mathrm{N}$, its apparent that the tectonic event $(C 4)$ is isolated at the end of a segment whereas the other events (swarm type) are spatially concentrated or organized along structures such as the neovolcanic on-axis ridge, in the center of ridge segments. At a shorter scale, Figure 10 shows the location of the sequences superimposed on the Mantle Bouguer Anomaly (MBA) map computed by Maia et al. [2007]. The locations of tectonic and magmatic clusters are well correlated with regions with positive and negative MBA values, respectively. This indicates the presence of thinner/colder and thicker/warmer crust, respectively. The good spatial correlation between "nontectonic" clusters and active volcanic structures of the MAR (e.g. neovolcanic ridges and negative MBAs) indicates the presence of a warmer and thicker crust consistent with magmatic source for these earthquake clusters.

\section{Conclusions}

[31] The SIRENA hydroacoustic experiment recorded monitored for 16 months the seismic and volcanic activity along a one-thousand-kilometer section of the Mid-Atlantic Ridge north of the Azores. This survey provides a key data set to understand the volcanic and tectonic processes occurring along a slow-spreading ridge in a ridge/hot spot interaction context, at various spatial and temporal scales. The spatial and temporal distribution of the seismicity recorded during the SIRENA experiment brings insights both into large-scale ridge-hot spot interactions and segment-scale active accretion processes.

[32] The long-term declustered distribution of the small-magnitude seismicity provides further evidence that the Azores hot spot exerts a strong influence on recent MAR accretion processes. The long-trend variations of this distribution further indicates that this influence has a rather limited northward extension, up to the relay zone located near $43^{\circ} 30^{\prime} \mathrm{N}$ [Goslin et al., 1998; Maia et al., 2007]. At a segment-scale, tectonic and nontectonic earthquake-generating processes can be viewed through the analysis of the time-distribution of earthquakes from several sequences. The locations of tectonic and "non-tectonic" sequences correlate well with regions exhibiting positive and negative MBAs, respectively. Detachment faults can also be evidenced using aftershocks spatial distribution. Such a correlation is in favor of the now-classical image of a thermally segmented slow-spreading Mid-Atlantic Ridge. 


\section{Acknowledgments}

[33] Funding from several sources made the SIRENA experiment possible. The cost of ship-time for the two cruises was provided by the French Ministry of Research. The development of the autonomous hydrophones, their building and deployment costs were provided by the NOAA Ocean Exploration Program and National Science Foundation (OCE-01). Finally, data interpretation was initiated while R. Dziak stayed in Brest for two months as an invited professor by the University of Brest. We thank the masters and crews of the $R / V$ Le Suroit and RRS Discovery for their help and seamanship during the deployment and recovery of the instruments. Discussions with A. Deschamps, M. Maia and C. Tisseau are gratefully acknowledged. This is NOAA/PMEL contribution 3792 and IPGP contribution 3262. We thank two anonymous reviewers and one associate editor who significantly contributed to improve the quality of the manuscript.

\section{References}

Albaric, J., J. Perrot, J. Déverchère, A. Deschamps, B. L. Gall, R. W. Ferdinand, C. Petit, C. Tiberi, C. Sue, and M. Songo (2010), Contrasted seismogenic and rheological behaviours from shallow and deep earthqauke sequences in the North Tanzanian Divergence, East Africa, J. Afr. Earth Sci., 58, 811-899.

Amante, C., and B. W. Eakins (2009), Etopo1 1 arc-minute global relief model: Procedures, data sources and analysis, NOAA Tech. Memo., NESDIS NGDC-24, Natl. Geophys. Data Cent., Boulder, Colo., March.

Baer, G., Y. Hamiel, Y. Shamir, and R. Nof (2008), Evolution of a magma-driven earthquake swarm and triggering of the nearby Oldoinyo Lengai eruption as resolved by InSAR, ground observations and elastic modeling, East African Rift, 2007, Earth Planet. Sci. Lett., 272, 339-352.

Balanche, A., C. Guennou, J. Goslin, and C. Mazoyer (2009), Generation of hydroacoustic signals by oceanic subseafloor earthquakes: A mechanical model, Geophys. J. Int., 177, 476-480.

Bell, R. E., and W. R. Buck (1992), Crustal control of ridge segmentation inferred from observations of the Reykjanes Ridge, Nature, 357, 583-586.

Bohnenstiehl, D. R., and M. C. Kleinrock (2000), Evidence for spreading-rate dependence in the displacement-length ratios of abyssal hill faults at mid-ocean ridges, Geology, 28, 395-398

Bohnenstiehl, D. R., and M. Tolstoy (2003), Comparison of teleseismic- and hydroacoustic-derived earthquake locations along the north-central Mid-Atlantic Ridge and equatorial East Pacific Rise, Seismol. Res. Lett., 74, 790-801.

Bohnenstiehl, D. R., M. Tolstoy, R. P. Dziak, C. G. Fox, and D. K. Smith (2002), Aftershock sequences in the mid-ocean ridge environment: An analysis using hydroacoustic data, Tectonophysics, 354, 49-70.

Cann, J. R., D. K. Blackman, D. K. Smith, E. McAllister, B. Janssen, S. Mello, E. Avgerinos, A. R. Pascoe, and J. Escartin (1997), Corrugated slip surfaces formed at ridge-transform intersections on the Mid-Atlantic Ridge, Nature, 385,329-332.

Cannat, M. (1993), Emplacement of mantle rocks in the seafloor at mid-ocean ridges, J. Geophys. Res., 98, 4163-4172.
Cannat, M. (1996), How thick is the magmatic crust at slowspreading ridge?, J. Geophys. Res., 101, 2847-2857.

Cannat, M., et al. (1995), How thick is the magmatic crust at slow-spreading ridge?, Earth Planet. Sci. Lett., 101, 2847-2857.

DeLong, S. E., J. Dewey, and P. J. Fox (1977), Displacement history of oceanic fracture zone, Geology, 5, 199-202.

Dziak, R. P. (2001), Empirical relationship of t-wave energy and fault parameters of northeast Pacific Ocean earthquakes, Geophys. Res. Lett., 28, 2537-2540.

Dziak, R. P., C. G. Fox, and A. E. Schreiner (1995), The JuneJuly 1993 seismo-acoustic event at CoAxial Segment, Juan de Fuca Ridge: Evidence for a lateral dike injection, Geophys. Res. Lett., 22, 135-138.

Dziak, R. P., D. R. Bohnenstiehl, H. Matsumoto, C. G. Fox, D. Smith, M. Tolstoy, T.-K. Lau, J. Haxel, and M. Fowler (2004a), P- and T-wave detection thresholds, Pn velocity estimate, and detection of lower mantle and core P-waves on ocean sound-channel hydrophones at the Mid-Atlantic Ridge, Bull. Seismol. Soc. Am., 95, 665-677.

Dziak, R. P., D. K. Smith, D. R. Bohnenstiehl, C. G. Fox, D. Desbruyeres, H. Matsumoto, M. Tolstoy, and D. J. Fornari (2004b), Evidence of a recent magma dike intrusion at the slow spreading Lucky Strike segment, Mid-Atlantic Ridge, J. Geophys. Res., 109, B12102, doi:10.1029/2004JB003141.

Dziak, R. P., D. R. Bohnenstiehl, H. Matsumoto, M. J. Fowler, J. H. Haxel, M. Tolstoy, and F. Waldhauser (2009), January 2006 seafloor-spreading event at $9^{\circ} 50^{\prime} \mathrm{N}$, East Pacific Rise: Ridge dike intrusion and transform fault interactions from regional hydroacoustic data, Geochem. Geophys. Geosyst., 10, Q06T06, doi:10.1029/2009GC002388.

Engeln, J. F., D. A. Wiens, and S. Stein (1986), Mechanisms and depths of Atlantic transform earthquakes, J. Geophys. Res., 91, 548-577.

Fox, C., R. Dziak, H. Matsumoto, and A. Schreiner (1994), Potential for monitoring low-level seismicity on the Juan de Fuca Ridge using military hydrophone arrays, Mar. Technol. Soc. J., 27, 22-30.

Fox, C. G., H. Matsumoto, and T.-K. Lau (2001), Monitoring Pacific Ocean seismicity from an autonomous hydrophone array, J. Geophys. Res., 106, 4183-4206.

Gac, S., J. Dyment, C. Tisseau, and J. Goslin (2003), Axial magnetic anomalies over slow-spreading ridge segments: Insights from numerical 3-D thermal and physical modelling, Geophys. J. Int., 154, 618-632.

Gac, S., C. Tisseau, J. Dyment, and J. Goslin (2006), Modelling the thermal evolution of slow-spreading ridge segments and their off-axis geophysical signature, Geophys. J. Int., 164, 341-358.

Galindo-Zaldívar, J., A. Jabaloy, A. Maldonado, J. M. MartínezMartínez, C. S. de Galdeano, L. Somoza, and E. Surinach (2000), Deep crustal structure of the area of intersection between the Shackleton fracture zone and the West Scotia Ridge (Drake Passage, Antartica), Tectonophysics, 320, 123-139.

Gente, P., R. A. Pockalny, C. Durand, C. Deplus, M. Maia, G. Ceuleneer, C. Mével, M. Cannat, and C. Laverne (1995), Characteristics and evolution of the segmentation of the MidAtlantique Ridge between $20^{\circ} \mathrm{N}$ and $24^{\circ} \mathrm{N}$ during the last10 million years, Earth Planet. Sci. Lett., 129, 55-71.

Goslin, J., J.-L. Thirot, O. Noel, and J. Francheteau (1998), Slow-ridge/hotspot interactions from global gravity, seismic tomography and ${ }^{87} \mathrm{Sr} /{ }^{86} \mathrm{Sr}$ isotopedata, Geophys. J. Int., $135,700-710$. 
Goslin, J., et al. (1999), Extent of Azores plume influence on the Mid-Atlantic Ridge north of the hotspot, Geology, 27, 991-994.

Goslin, J., et al. (2004), Interactions between the MAR and the Azores hotspot as imaged by seismicity distributions using autonomous hydrophone arrays, paper presented at Workshop on Seismo-acoustic Applications in Marine Geology and Geophysics, Woods Hole Oceanogr. Inst., Woods Hole, Mass., 24-26 March.

Goslin, J., N. Lourenço, R. P. Dziak, D. R. Bohnenstiehl, J. Haxel, and J. Luis (2005), Long-term seismicity of the Reykjanes Ridge (North Atlantic) recorded by a regional hydrophone array, Geophys. J. Int., 162, 516-524.

Haskov, J., and L. Ottemoller (2008), Seisan: The earthquake analysis software for Windows, Solaris, Linux and MacOSX, version 8.2, technical report, 281 pp., Dep. of Earth Sci., Univ. of Bergen, Bergen, Norway.

Ildefonse, B., D. K. Blackman, B. E. John, Y. Ohara, D. J. Miller, C. J. MacLeod, and Integrated Ocean Drilling Program Expeditions 304/305 Science Party (2007), Oceanic core complexes and crustal accretion at slow-spreading ridges, Geology, 35, 623-626.

Johnson, R. H., J. Northrop, and R. Eppley (1963), Source of Pacific T-phases, J. Geophys. Res., 68, 4251-4260.

Kuo, B.-Y., and D. W. Forsyth (1988), Gravity anomalies of the ridge-transform system in the South Atlantic between 31 and $34.5^{\circ} \mathrm{S}$ : Upwelling centers and variations in crustal thickness, Mar. Geophys. Res., 10, 205-232.

Leet, L. D., D. Linehan, and P. Berger (1951), Investigation of the T-phases, Bull. Seismol. Soc. Am., 41, 123-141.

Lin, J., G. M. Purdy, H. Schouten, J.-C. Sempere, and C. Zervas (1990), Evidence from gravity data for focused magma accretion along the Mid-Atlantic Ridge, Nature, 344, 627-632.

Magde, L. S., D. W. Sparks, and R. S. Detrick (1997), The relationship between buoyant mantle flow, melt migration and gravity bull's eyes at the Mid-Atlantic Ridge between $33^{\circ} \mathrm{N}$ and $35^{\circ} \mathrm{N}$, Earth Planet. Sci. Lett., 148, 59-67.

Magde, L. S., A. H. Barclay, D. R. Toomey, R. S. Detrick, and J. A. Collins (2000), Crustal magma plumbing within a segment of the Mid-Atlantic Ridge, $35^{\circ} \mathrm{N}$, Earth Planet. Sci. Lett., 175, 55-67.

Maia, M., J. Goslin, and P. Gente (2007), Evolution of the accretion processes along the Mid-Atlantic Ridge north of the Azores since 5.5 Ma: An insight into the interactions between the ridge and the plume, Geochem. Geophys. Geosyst., 8, Q03013, doi:10.1029/2006GC001318.

Mogi, K. (1963), Some discussionson aftershocks, foreshocks, and earthquake swarms - The fracture of a semi-infinite body caused by an inner stress origin and its relation to the earthquake phenomena, Bull. Earthquake Res. Inst. Univ. Tokyo, 41, 615-658.

Ogata, Y. (1983), Estimation of the parameters in the modified Omori formula for aftershocks frequencies by the maximum likehood procedure, J. Phys. Earth, 31, 115-124.

Okal, E. A. (2008), The generation of T-waves by earthquakes, Adv. Geophys., 49, 1-70.

Pan, J., and A. M. Dziewonski (2005), Comparison of midoceanic earthquake epicentral differences of travel time, centroid locations, and those determined by autonomous underwater hydrophone arrays, J. Geophys. Res., 110, B07302, doi:10.1029/2003JB002785.

Rommevaux, C., C. Deplus, P. Patriat, and J.-C. Sempéré (1994), Three-dimensional gravity study of the mid-atlantic ridge: Evolution of the segmentation between $28^{\circ}$ and $29^{\circ} \mathrm{N}$ during the last 10 m.y., J. Geophys. Res., 99, 3015-3029.

Simão, N., J. Escartin, J. Goslin, J. Haxel, M. Cannat, and R. Dziak (2010), Regional seismicity of the Mid-Atlantic Ridge: Observations from autonomous hydrophone arrays, Geophys. J. Int., 183, 1559-1578.

Smith, D. K., M. Tolstoy, C. G. Fox, D. R. Bohnenstiehl, H. Matsumoto, and M. J. Fowler (2002), Hydroacoustic monitoring of seismicity at the slow-spreading Mid-Atlantic Ridge, Geophys. Res. Lett., 29(11), 1518, doi:10.1029/ 2001GL013912.

Sykes, L. R. (1970), Earthquake swarms and sea-floor spreading, J. Geophys. Res., 32, 6598-6611.

Talandier, J., and E. A. Okal (1998), On the mechanism of conversion of seismic waves to and from T-waves in the vicinity of island shores, Bull. Seismol. Soc. Am., 88, 621-632.

Thibaud, R., P. Gente, and M. Maia (1998), A systematic analysis of the Mid-Atlantic Ridge morphology and gravity between $15^{\circ} \mathrm{N}$ and $40^{\circ} \mathrm{N}$ : Constraints on the thermal structure, J. Geophys. Res., 103, 24,223-24,243.

Tolstoy, M., D. Bohnenstiehl, M. Edwards, and G. Kurras (2001), Seismic character of volcanic activity at the ultraslow-spreading Gakkel Ridge, Geology, 29, 1139-1142.

Utsu, T. (1995), The centenary of the Omori formula for a decay law of aftershock activity, J. Phys. Earth, 43, 1-33.

Utsu, T., and Y. Ogata (1997), Statistical analysis of seismicity, in IASPEI Software Library, vol. 6, edited by J. H. Healy, V. I. Kelis-Borok, and W. H. K. Lee, pp. 13-94, Int. Assoc. of Seismol. and Phys. of the Earth's Inter., Trieste, Italy.

Wiens, D. A., and S. Stein (1984), Intraplate seismicity and stresses in young oceanic lithosphere, J. Geophys. Res., 89, $11,442-11,464$. 